\title{
Open Innovation: a Way Forward For Small and Medium Enterprises (SME) In the Developing Countries to Become Sustainable
}

\author{
Saeed AMER, Yun Jun \\ School of Management, \\ Wuhan University of Technology, \\ Wuhan, 430070, China, \\ E-mail: amersaeed@whut.edu.cn, \\ yunjunwh@163.com
}

\author{
Ahmad AYAZ \\ Lahore Business School \\ University of Lahore (UOL) \\ Lahore, Pakistan 54000 \\ E-mail: ayaz.ahmad@lbs.uol.edu.pk
}

\begin{abstract}
Increased trend of globalization and focus on environment friendly processes and products has make it a biggest challenge for small and medium size enterprises (SME's) to play their active and equal role as compare to large multinational corporations (MNC's). SME's play a significant role in the overall supply chains around the globe and specifically in the economies of the developing countries. To meet the challenges of becoming green SME's in the developing countries need to follow business models based upon open innovation paradigm. This conceptual study reveals that by inbound knowledge sharing SME's can enhance their capabilities to mitigate environmental issues. At the same time by making inter and intra industry clusters and by using unique localized tacit knowledge they could come up with indigenous processes and products which they can offer to other companies including MNC's around the globe.
\end{abstract}

Keywords-Open Innovation; SME's; Green supply chain management; Sustainability; Developing countries

\section{INTRODUCTION}

Business today is in a global environment. This environment forces organizations of all sizes to consider rest of the world in their competitive strategy analysis. Multinational corporations (MNCs) benefit from globalization and they have emerged as major actors of global economy and expanded their business activities worldwide [1]. But for SME's it is not an easy task to compete not only with the local companies but also with the giants of the industry worldwide. On the same time SME's have become an important link as competition is moving towards supply chain versus supply chain at a very high pace [2]. Due to this type of competition, companies irrespective of their size are becoming global.

Supply chain management has become an area of strategic importance because of global competition, outsourcing of non-core activities to developing countries, shorter product lifecycle and limited time span in all aspects of supply chain [3]. At the same time environmental consciousness has become critical in the design and operation of globally integrated supply chain networks. Various groups across social and economic spectrum have expressed their concern about environmental degradation caused by the industrial activity and demanded greater awareness with respect to business decisions that might have potential impact on the environment [1]. One of the biggest pressures to improve their environmental performance come from globalization rather than localization [4].

With rapid economic growth, the increasing urbanization, and accelerated integration into the world market, implementation of green supply chain management (GSCM) has been observed in developed as well as developing countries. The quest for more efficient supply chain organization has been considered as a driving force for the future growth of green industries in developing countries [5]. The MNC's focus on developing countries with respect to green initiatives has not been given much attention. And very little attention has been given to the role of SME's in developing countries with respect to damaging or improving the environmental conditions. The impact of greening initiatives by these SME's could be even higher than MNC's due to their large number. This study is an attempt to find out the reasons to be green and how SME's can achieve this target by keeping limitation of resources in mind. The study aim to answer following research questions;

- What are the driving forces behind the development of GSCM strategies in global supply chains?

- What is the importance of SME's in global supply chains?

- Can open innovation help SME's to survive and thrive?

This paper is conceptual in nature and an attempt to explore the relationship between endeavors of sustainability of SME's in developing countries through open innovation. The paper is organized in four sections. First section presents the introduction, research questions and relative importance of the study. Second section presents detailed literature review on GSCM, its relation and importance for SME's in developing countries and the role of open innovation for SME's to achieve sustainability. Third section presents limitations of the study, future research directions and fourth section gives the conclusion.

\section{LITERATURE REVIEW}

Several companies are involved in international supply chains in various ways, ranging from simple import and export activities to the development of subsidiaries in 
foreign countries. Although global configurations of firms provide access to cheap labor and raw material, better financing opportunities, large product markets and opportunities to attract foreign capital. However along with these opportunities there are certain risks that companies might face while operating in global supply chains [6]. These risks involve supply, demand operational and security risks. At the same time many stake holders including consumers, shareholders, non-government organizations, public authorities and trade unions are showing an increasing interest in environmental issues to international business.

\section{GLOBALIZATION AND ENVIRONMENT}

The forces of globalization in the present business world are unstoppable. The word of globalization has evolved everywhere and implies a strong cultural, technological and economic interconnection between people and countries. However the acceleration of globalization has also created environmental issues for companies [7]. The manufacturing activity has led to environmental degradation and depletion of natural resources. The environment represents a key element for companies. It provides raw material and energy resources for their industrial activities. MNCs are in a position to impact environment negatively as well as positively. They may adversely impact the environment by production of greenhouse gases, production and emission of hazardous and toxic substances. On the other hand they have the ability to impact the environment positively through development of new environmental friendly technologies and management practices. Therefore regarding the positive impact of MNCs on environment it must be considered that they are in a better position to improve environmental conditions through their technologies and R\&D capabilities [1]. Many companies have experienced increasing globalization and a shifting focus to competition among networks of companies. Logistics and supply chain managers have to balance efforts to reduce cost and innovate while maintaining environmental performance.

Globalization has increased the influence of regulation and customers in countries from which foreign investment is originating or that are destinations of exports from developing countries. Empirical evidence shows that MNCs in developing countries are motivated by regulatory and market pressures from customers, investors and NGOs in countries where there major markets are located [8]. MNCs that adopt ISO 14001 and other environmental management systems are more likely to examine the environmental performance of their suppliers [9].

\section{GREEN SUPPLY CHAIN MANAGEMENT (GSCM)}

GSCM involves the integration of environmental thinking into supply chain management including product design, supplier selection, material sourcing, manufacturing processes, product packaging, delivery of product to the end consumer and end of life management of the products after their usage [10, 11]. In other words responsible environmental and social behavior must be promoted for the benefit of the entire supply chain [12].
GSCM is considered as a way to create economic value [13]. It considers SCM as a collaborative process involving several entities both internal and external and at multiple levels of the organizational structure. Each seemingly independent supply chain decision carries the risk of potentially harming the environment when it is magnified multiple times through the global supply chain. On the other hand more sustainable supply chain in the global context may help in improving the overall performance of the supply chain thus creating a competitive advantage for members across the supply chain [14].

\section{ENVIRONMENTAL INITIATIVES OF MNCS IN DEVELOPING COUNTRIES}

Economic growth in industrializing developing countries is accompanied by substantial environmental degradation leading to negative implications for productivity and human health. MNCs account for a relatively small share of production in most of the developing countries and most of the economic activity occurs through the domestic firms. Moreover customer pressure from rich countries is selective in its focus on developing countries products and practices that has more symbolic value than environmental significance [8]. Insufficient integration of some sectors of economy coupled with week regulatory pressures domestically may also prevent the implementation of green SCM in developing countries. Regulatory institutions in developing countries are weak and have a limited capacity to monitor enforcement of environmental regulations and practices. The study of developing counties provides the evidence that lobbying and corruption are the hindrances in the way of successful implementation of pollution control laws $[15,16]$.

\section{INTERNAL STAKEHOLDERS}

The internal stakeholders involve corporate office, shareholder management, and non-management employees which are significant to the success and failure of the firms' overall environmental strategy. The internal pressures from top management, shareholders and employees are considered key determinants for adoption of proactive environmental practices by the firms. The firms that receive greater pressures from internal stakeholders are more likely to adopt the proactive environmental management practices [17].

\section{EXTERNAL STAKEHOLDERS}

The external stakeholders are usually institutional actors which include government regulations (coercive Pressures); industry/ trade associations, environmental groups/ organizations, labor unions, (normative pressures); market and business pressures (mimetic) pressures.

MNCs that operate in different countries face many challenges as laws and regulations in different countries can vary extensively [14]. The current state and trend of environmental issues and pressures from stakeholders force manufacturing companies to adopt environmental initiatives through waste reduction and making efficient and effective 
use of resources [18]. For example European Union Has recently emphasized the restriction on electrical and electronic waste equipment and hazardous waste materials. They have also started an intensive $3 \mathrm{R}$ campaign with a purpose and promoting re-use, re-cycle and reducing the use of hazardous substances in the market. Because of these initiatives upstream and downstream manufacturers face tremendous pressure to work together on green management practices [19]. Sometimes the company itself pushes the creation of regulations if it has developed an environmental friendly technology and believes that the rules requiring this technology would give it a competitive advantage [20]. A vast number of different codes of conduct, different standards, certification schemes, eco labels, and system of global governance that affect MNCs as well as smaller companies [21].

\section{INNOVATION AND OPEN INNOVATION}

Innovation can be defined as a creative design, enhancement or invention of a new product or service to get more better functional and economical results. Its ultimate target is to improve knowledge that will leads towards much better financial growth [22, 23].

Open innovation, on the other hand, incorporates joint efforts from in-house capabilities and possible outsourcing or combination of several input paths during the product or service development. As [24] defined OI as "open innovation is the use of purposive inflows and outflows of knowledge to accelerate internal innovation, and expand the markets for external use of innovation, respectively". In this regard appropriate use of planned and properly administered inflow and outflow of knowledge will leads to responsiveness of supply chain by timely designing, producing and marketing of the products. And this improved value chain will ultimately increase the shareholders' value [25].

Properly designed business model is the key to success of an OI based working organization. As business models can easily be interpreted and copied in today's business environment, the competitive advantage can be developed and kept for a longer period of time by developing non imitable human resources within the organization or making a strong and long term relationship with the organizations within the supply chain. SME's in any supply chain could be a larger and critical part at different levels so their role become critical in the effective implementation of OI based business model [26].

MNC's in any supply chain could take a role of mentor or facilitator and by focusing on their own core competencies they can bring SME's on the forefront for multiple innovative tasks. This could be achieved by a systematic way of knowledge sharing, concentrated trainings, organized deregulation and enhancing the capacity to innovate for the SME's [23]. SME's need to think about their weaknesses and strengths. Lack of financial resources and advanced technology are the biggest of the issues for them in almost all the developing countries [27]. Irrespective of many challenges, SME's might have some advantages over big corporations coming from abroad. They might have better and in depth knowledge of local markets, sources of raw materials, communication styles and above all the tacit knowledge regarding processing, handling and/ or production of certain raw materials to produce a final product. For example, certain cities in Pakistan have specialization regarding leather, textile, cutlery and other related products. Almost every family in these areas has some sort of connection with the production of these products. Many generations have transferred their expertise and experiences to manufacture those products. Now with the help of technology along with that experience of generations can make wonders.

Open innovation emerges on issues like, in the diverse world of widely distributed knowledge, individual enterprises cannot afford (economically and organizationally) to rely entirely on their own research and resources, but may instead collaborate, buy, lease-out or license processes or inventions (patents, intellectual properties) from other companies, organizations or institutions [25]. In addition, internal inventions that are not being used in a company's business process should be taken outside the company (through licensing, joint ventures, spin-offs) [26].

Making a cluster of SME's in same industry might be highly beneficial for many reasons. They can buy a technology by combining the resources and then develop their internal expertise according to their own needs and capabilities [28]. Cluster of SME's from different industries can also be formed to share knowledge, experiences and advancement in their respective areas. In this regard they might get benefit from each other resources. It is quite possible that an established process in one industry could become a guideline for some other industry. A company might be best in class or even world class in certain process could sell its expertise to companies working in other sectors and having similar needs.

\section{LIMITATIONS AND FUTURE RESEARCH DIMENSIONS}

There are certain limitations associated with this study that open way for future research. It was a conceptual work as both sustainable supply chain management and open innovation concepts are in developing stage. More and more exploration of these concepts through case studies are required which could be empirically tested afterwards. Multiple case studies from multiple developing countries could be even better approach to make the results more generalizable.

\section{CONCLUSION}

Environmental conditions around the globe calls for responsibility and cooperation of all players in a supply chain. Environmental standards apply for all operations everywhere and throughout the supply chain. Large corporations have the financial and technological resources to meet these challenges and even find the business opportunities out of it. SME's specifically in developing countries need to adopt new ways of doing business and thinking more innovatively to survive in such a situation. 
Following open innovation gives them an opportunity to share knowledge both ways i.e. inbound and outbound to enhance their capabilities to meet the requirements of government legislations, big importers from developed countries, civil societies and consumers. By making clusters within the industry and intra industry can help them to meet the challenges of financial resources as well developing their indigenous cost effective technological solutions. Such solutions could not only minimize the harm to the environment but also minimized the production cost in the longer run. The most uniformly successful way to promote improved environmental performance is through the supply chain. No supplier will ignore a justified request from an important buyer who wants to know the suppliers environmental performance. This study has identified that buyer- supplier collaboration on environmental issues through open innovation results in better economic and environment incentives for both buyer and supplier. Lessons from these experiences should be examined and disseminated to improve business and environmental management practices.

\section{REFERENCES}

1. D.I. Márquez, The green side of the International Codes of Conduct for Business. 2014.

2. Chen, I.J. and A. Paulraj, "Towards a theory of supply chain management: the constructs and measurements", Journal of operations management, vol. 22, pp. 119-150,Feb. 2004.

3. A. Halldorsson, et al., "Complementary theories to supply chain management", Supply Chain Management: An International Journal, vol. 12, pp. 284-296,Apr. 2007.

4. A.A. Hervani, , M.M. Helms, and J. Sarkis, "Performance measurement for green supply chain management",Benchmarking: An International Journal, vol.12, pp. 330-353, Apr., 2005.

5. S.B. Tiwari, "Challenges and Prospects of Emerging Management and Accounting of Green Supply Chain in the Next Millennium" International Journal of Scientific and Research Publications, 3rd, 2013.

6. I. Manuj, and J.T. Mentzer, "Global supply chain risk management strategies", International Journal of Physical Distribution \& Logistics Management, vol. 38, pp. 192-223, Mar. 2008.

7. J. Sarkis, "Manufacturing's role in corporate environmental sustainability", International journal of operations management, 2(5/6): pp. 666-686, 2001.

8. Khanna, M. and Y. Liao, Globalization and Voluntary Environmental Management in Developing Countries. Front. Econ. China. vol. 9, pp. 138-163, Jan. 2014.

9. Jabbour, C.J.C., et al., "Eco-innovations in more sustainable supply chains for a low-carbon economy: A multiple case study of human critical success factors in Brazilian leading companies", International Journal of Production Economics, vol. 164, pp. 245-257, 2015.

10. J. Linton, R. Klassen, V.Jayaraman, "Sustainable supply chains:an introduction", Journal of operations management, vol.25, pp. 10751082,June 2007.
11. S.K. Srivastara, "Green supply chain management:a state-of-the-art literature review", International journal of management reviews, vol. 9, pp. 53-80, Jan. 2007.

12. Testa, F.a.I., F., Shadows and Lights of GSCM (Green Supply Chain Management): Determinants and Effects of These Practices Based on a Multi-City Study. Journal of cleaner production, vol. 18, p. 853-962, 2010.

13. Mefford, R., The Economic Value of a Sustainable Supply Chain. Business and Society Review, vol.116, pp. 109-143, Jan. 2011.

14. Wu, J., S. Dunn, and H. Forman, A study on green supply chain management practices among large global corporations. Journal of Supply Chain and Operations Management, pp. 182-194, vol.10,Jan. 2012.

15. Mitra, S., Corruption, pollution, and the Kuznets environment curve. Journal of Environmental Economics and Management, vol.40. pp. 137-150, Feb. 2000.

16. McAllister, L.K., B. Van Rooij, and R.A. Kagan, Reorienting regulation: pollution enforcement in industrializing countries. Law \& Policy, vol.32, pp. 1-13, Jan. 2010.

17. Singh, N., S. Jain, and P. Sharma, Determinants of proactive environmental management practices in Indian firms: an empirical study. Journal of Cleaner Production, vol.66, pp. 469-478, 2014.

18. Handfield R., S.R., and Walton S., Integrating Environmental Management and Supply Chain Strategies. Business Strategy and Environment, vol14, pp. 1-19, 2005.

19. Muslan, N., et al., Practices of Green Supply Chain Management (GSCM) towards Manufacturing Sustainability. International Proceedings of Economics Development \& Research, vol66, 2013.

20. Kleindorefer, P.R.S., K.; Wassenhove, L.N.D.. Sustainable Operations Management. Production and Operations Management, vol.14, Apr. 2005, pp. 482-492, Apr. 2005.

21. Conroy, M.E., How the Certification Revolution" is Transforming Global Corporations. New Society Publishers, Gabriola Island, Canadá,. 2007.

22. Detre, J.D., A.J. Johnson, and A.W. Gray, Innovativeness and innovation: Implications for the renewable materials supply chain International Food and Agribusiness Management Review,vol.14, pp. 17-34, 2011.

23. Rahman, H. and I. Ramos, Open Innovation in SMEs: From closed boundaries to networked paradigm. Issues in Informing Science and Information Technology, vol.7, pp. 471-487, 2010.

24. Chesbrough, H., W. Vanhaverbeke, and J. West, Open innovation: Researching a new paradigm, Oxford university press, 2006.

25. De Jong, J.P., et al., Policies for open innovation: Theory, framework and cases, Tarmo Kalvet, 2008.

26. Bianchi, M., et al., Enabling open innovation in small-and medium - sized enterprises: how to find alternative applications for your technologies. R\&d Management, vol.40, pp. 414-431, Apr. 2010.

27. Andreassi, T., Innovation in small and medium-sized enterprises. International Journal of Entrepreneurship and Innovation Management, vol.3, pp. 99-106, 2003.

28. West, J. and S. Gallagher, Open Innovation: The Paradox of Firm Investment in Open Source Software. Silicon Valley Open Source Research Project, 2004. 